\title{
Inhibition of PI3K by PX-866 Prevents Transforming Growth Factor- $\alpha$-Induced Pulmonary Fibrosis
}

Timothy D. Le Cras, ${ }^{*}$ Thomas R. Korfhagen, ${ }^{*}$ Cynthia Davidson, ${ }^{\dagger}$ Stephanie Schmidt, ${ }^{\dagger}$ Matthew Fenchel, ${ }^{\dagger}$ Machiko Ikegami, ${ }^{*}$ Jeffrey A. Whitsett, ${ }^{*}$ and William D. Hardie ${ }^{\dagger}$

From the Divisions of Pulmonary Biology* and Pulmonary Medicine, ${ }^{\dagger}$ Cincinnati Children's Hospital Medical Center, Cincinnati, Obio

Transforming growth factor- $\alpha$ (TGF $\alpha$ ) is a ligand for the epidermal growth factor receptor (EGFR). EGFR activation is associated with fibroproliferative processes in human lung disease and animal models of pulmonary fibrosis. EGFR signaling activates several intracellular signaling pathways including phosphatidylinositol 3'-kinase (PI3K). We previously showed that induction of lung-specific TGF $\alpha$ expression in transgenic mice caused progressive pulmonary fibrosis over a 4-week period. The increase in levels of phosphorylated Akt, detected after 1 day of doxycycline-induced TGF $\alpha$ expression, was blocked by treatment with the PI3K inhibitor, PX-866. Daily administration of PX-866 during TGF $\alpha$ induction prevented increases in lung collagen and airway resistance as well as decreases in lung compliance. Treatment of mice with oral PX-866 4 weeks after the induction of TGF $\alpha$ prevented additional weight loss and further increases in total collagen, and attenuated changes in pulmonary mechanics. These data show that PI3K is activated in TGF $\alpha$ /EGFR-mediated pulmonary fibrosis and support further studies to determine the role of PI3K activation in human lung fibrotic disease, which could be amenable to targeted therapy. (Am J Pathol 2010, 176:679-686; DOI: 10.2353/ajpath.2010.090123)

Pulmonary fibrosis contributes to morbidity and mortality in a number of pediatric and adult lung diseases. Clinical diseases causing pulmonary fibrosis are heterogeneous, and fibrosis may develop secondary to acute lung injury such as in acute respiratory distress syndrome, from chronic inflammatory diseases as in cystic fibrosis, or from unknown causes such as in idiopathic pulmonary fibrosis. While the pathological features of pulmonary fibrosis may vary depending on the underlying disease process, a number of common characteristics include mesenchymal cell proliferation, expansion of the extracellular matrix, and remodeling of the lung parenchyma. ${ }^{1}$ Currently there are no proven therapies that prevent or reverse pulmonary fibrosis, emphasizing the need to identify new therapeutic targets.

Epidermal growth factor receptor (EGFR/HER1) belongs to a receptor tyrosine kinases protein family that also includes HER2/neu, HER3 and HER4. Six EGFR ligands (transforming growth factor $\alpha$ [TGF $\alpha$ ], epidermal growth factor [EGF], heparin binding EGF-like growth factor, amphiregulin, betacellulin, and heregulin) have been identified in lungs or lung cells..$^{2-8}$ Depending on the activating ligand, EGFR family members form homodimers or heterodimers with different biological capacities. ${ }^{9,10}$ Activation of EGFR is known to regulate diverse cellular functions, many of which are associated with fibrogenesis, including cell growth, proliferation, differentiation, migration, protection from apoptosis, and transformation. ${ }^{11,12}$ We have previously generated doxycycline (Dox)-regulatable transgenic mice wherein lung epithelial-specific expression of TGF $\alpha$ caused progressive and extensive vascular adventitial, peribronchial, interstitial, and pleural fibrosis that was independent of inflammation. ${ }^{13}$ Gene expression profiles observed after expression of TGF $\alpha$ in the mouse lung were similar to those found in human fibrotic lung disease. ${ }^{14}$

The signaling pathways downstream of EGFR activation that mediate TGF $\alpha$-induced pulmonary fibrosis are unknown. Following ligand binding to the extracellular domain, receptor homodimers and heterodimers lead to auto- or transphosphorylation by intrinsic tyrosine-kinase activity on specific residues in the cytoplasmic domains. The phosphorylated tyrosine residues become docking sites for signaling molecules that activate multiple downstream effecter pathways including the RAS/RAF/mito-

Supported by The American Heart Association and National Institutes of Health grants AHA 740069N (T.D.L.), HL058795 (T.K.), HL90156 (J.A.W.), and HL086598 (W.D.H.).

Accepted for publication October 21, 2009.

Address reprint requests to William D. Hardie, M.D., Department of Pulmonary Medicine, Cincinnati Children's Hospital Medical Center, 3333 Burnet Avenue, Cincinnati, OH 45229. E-mail: william.hardie@cchmc.org. 


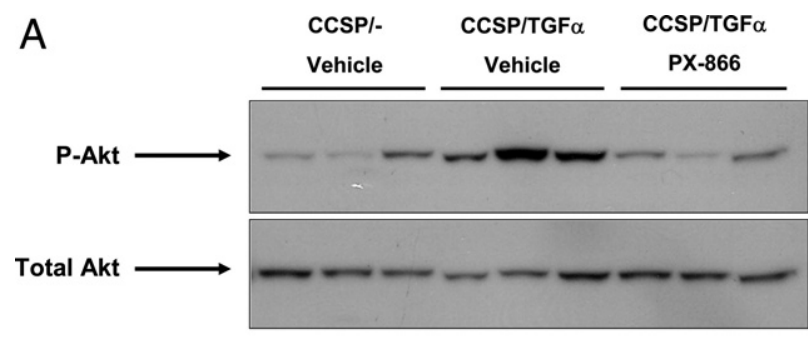

B

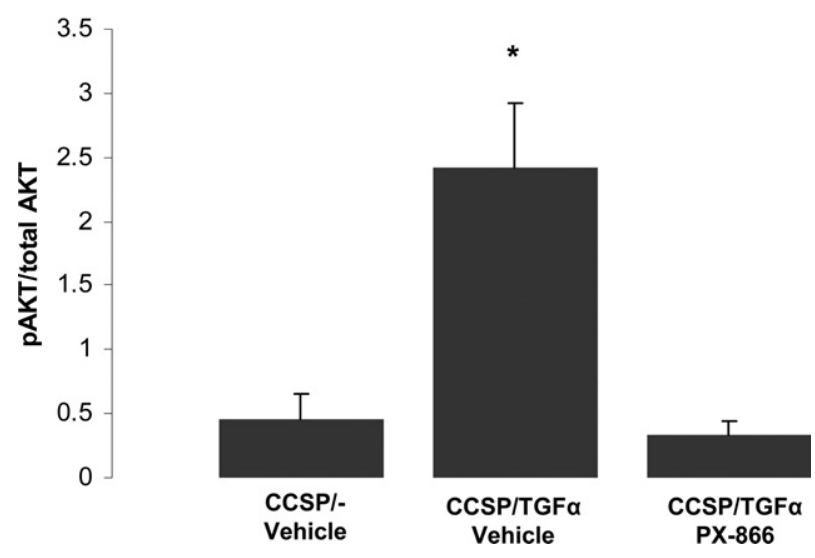

Figure 1. PX-866 inhibits TGF $\alpha$-induced phosphorylation of Akt (P-Akt) Western blot analysis was used to determine levels of phosphorylated and nonphosphorylated Akt in lung homogenates. P-Akt levels in CCSP/TGF $\alpha$ transgenic mice increased over fivefold after 1 day of Dox-induced TGF $\alpha$ expression compared with Dox-treated single transgene $(\mathrm{CCSP} /-)$ controls Pretreatment of CCSP/TGF $\alpha$ mice with PX-866 prevented increased phosphorylation of Akt. Representative samples in (A) are three separate mice in each group. Values in $(\mathbf{B})$ are mean $\pm \mathrm{SE}, n=6$ in each group. ${ }^{*} P<0.05$, as compared with CCSP/- controls and PX-866-treated mice.

gen-activated protein kinase cascade, the JAK/STAT pathway, the phospholipase $\mathrm{C} \gamma$ pathway and the phosphatidylinositol $3^{\prime}$-kinase (PI3K)/Akt signaling pathway. ${ }^{11}$

$\mathrm{PI} 3 \mathrm{~K}$ is a signal transduction enzyme that catalyzes the phosphorylation of phosphatidylinositol $(4,5)$-biphosphate to form phosphatidylinositol $(3,4,5)$-triphosphate in response to activation of receptor tyrosine kinases, Gprotein coupled receptors or cytokine receptors. Phosphatidylinositol $(3,4,5)$-triphosphate in turn phosphorylates Akt by pyruvate dehydrogenase kinase 1 and/or 2 and has been associated with a number of profibrotic cellular processes including cell growth, proliferation, migration, survival and collagen gene expression. ${ }^{15}$ PX-866 is an orally available nanomolar pan-inhibitor of PI3K whose administration results in antitumor activity and pathway inhibition in animal models. ${ }^{16-18}$ As stimulation of the PI3K pathway may be the major mediator of the cellular effects of EGFR activation ${ }^{12}$ we hypothesized that the PI3K-Akt pathway mediates TGF $\alpha$-induced pulmonary fibrosis. In this study we determined the role of PI3K in the initiation and propagation of pulmonary fibrosis by administering PX-866 at the time of TGF $\alpha$ induction in regulatable transgenic mice. In addition, we determined the effectiveness of PI3K inhibition as a treatment for established fibrosis in the TGF $\alpha$ model by administering PX-866 after fibrosis was pronounced and progressing.

\section{Materials and Methods}

\section{Transgenic Mice and Administration of PX-866}

CCSP-rtTA activator mice expressing the reverse tetracycline-responsive transactivator (rtTA) under control of the 2.3-kb rat Clara Cell Secretory Protein (CCSP), a.k.a. secretoglobin, family 1A, member 1 (Scgb1a1) gene promoter ${ }^{19}$ were mated to conditional Dox-regulated transgenic mice containing the human TGF $\alpha$ cDNA under the control of seven copies of the tetracycline operon, (TetO) ${ }_{7}-c m v$ TGF $\alpha$, plus a minimal CMV promoter. ${ }^{13} \mathrm{Sin}-$ gle transgenic (CCSP-rtTA ${ }^{+/-}$mice, (hereafter abbreviated CCSP $/-$ ) and bitransgenic CCSP-rtTA ${ }^{+/-} /\left(\right.$TetO $_{7^{-}}$ cmv TGF $\alpha^{+/-}$mice (hereafter abbreviated CCSP/TGF $\alpha$ ) were produced within the same litter by mating homozygous CCSP/- mice to hemizygous (TetO) $)_{7}-\mathrm{Cmv}_{\mathrm{TGF}}{ }^{+/-}$
A
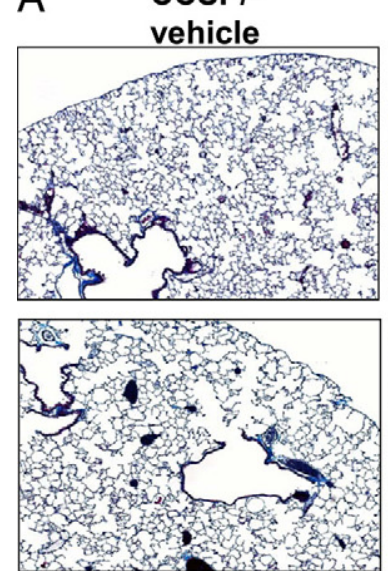

CCSP/TGF $\alpha$ vehicle
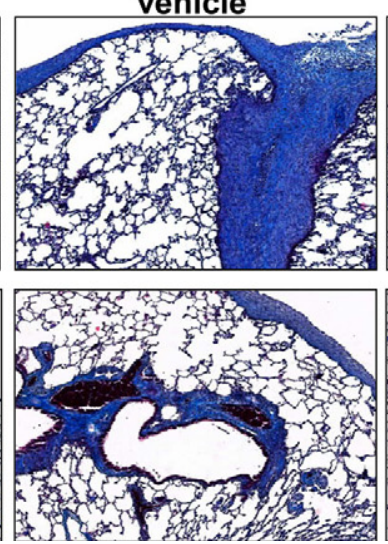

CCSP/TGF $\alpha$ PX-866
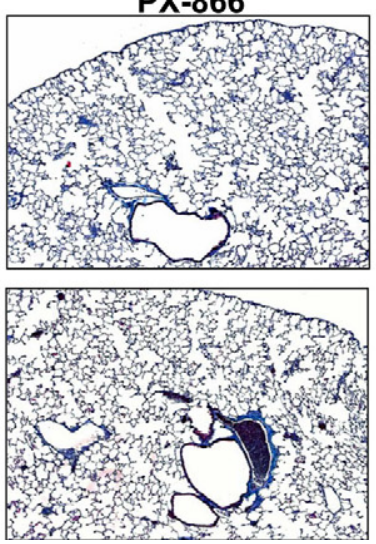

B

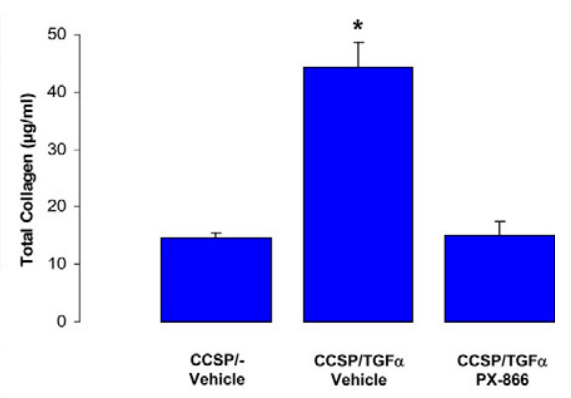

Figure 2. PX-866 prevents establishment of pulmonary fibrosis. Sections of lungs from control CCSP/- and CCSP/TGF $\alpha$ transgenic mice following 4 weeks of Dox were stained with trichrome (A). CCSP/TGF $\alpha$ transgenic mice administered PX-866 at the initiation of TGF $\alpha$ induction demonstrated marked attenuation of fibrosis, as compared with vehicle-treated CCSP/TGF $\alpha$ mice. Photomicrographs for each group are from two separate animals and are representative of lungs from five to seven mice in each group. Upper panel is taken at $\times 5$ magnification with lower panel at $\times 10$ magnification. Lung collagen content was determined from lungs of transgenic mice as described in Materials and Methods. PX-866 administered at the time of TGF $\alpha$-induction prevented increases in lung collagen B: Values are mean \pm SE. ${ }^{*} P<0.05$ compared with CCSP $/-$ controls and PX-866-treated mice. 


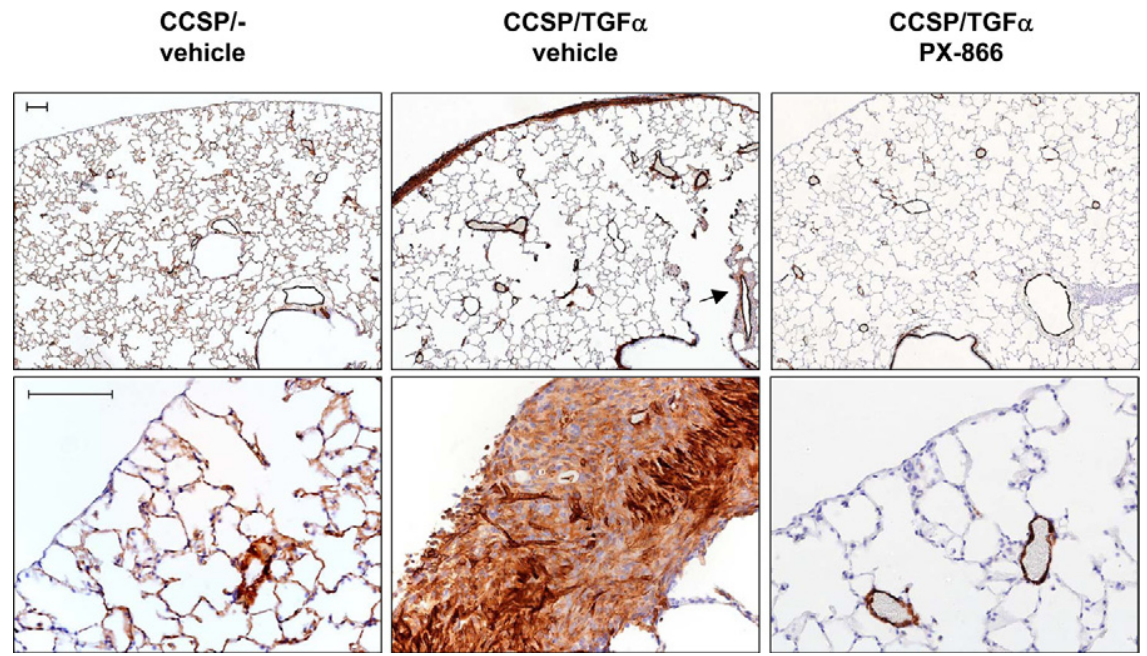

Figure 3. PX-866 prevents increased SMA deposition. Sections of lungs from control CCSP/and $\operatorname{CCSP} / \mathrm{TGF} \alpha$ transgenic mice following 4 weeks of Dox were stained with SMA. CCSP/ TGF $\alpha$ transgenic mice administered vehicle demonstrate marked SMA staining in the adventitia (arrow upper panel) and pleural regions while mice treated with PX-866 have no change in staining compared with controls. Upper panel is taken at $\times 5$ magnification with lower panel at $\times 20$ magnification. Scale bar $=100 \mu \mathrm{m}$. Photomicrographs for each group are from two separate animals and are representative of lungs from five to seven mice in each group.

mice. All mice were derived from the FVB/NJ inbred strain. Mice were maintained in virus-free containment. All animal protocols were reviewed and approved by the Institutional Animal Use and Care Committee of the Cincinnati Children's Hospital Research Foundation. To induce TGF $\alpha$ expression, Dox (Sigma, St. Louis, MO) was administered in the drinking water at a final concentration of $0.5 \mathrm{mg} / \mathrm{ml}$ and in food $(62.5$ $\mathrm{mg} / \mathrm{kg}$ ). Water was replaced three times per week.

The PI3K inhibitor PX-866 (Oncothyreon Inc., Seattle, WA) was suspended in $5 \%$ ethanol to make a $5 \mathrm{mg} / \mathrm{ml}$ stock solution. Three hours before administration, food and water were removed from cages. Mice were then anesthetized (Isoflurane; Abbott Labs, Chicago, IL), and sterile vehicle or drug $(3 \mathrm{mg} / \mathrm{kg})^{16,18}$ was administered by gavage using a 20 gauge feeding catheter (Harvard Apparatus, Holliston, MA). Dosing throughout the study was based on original baseline weights and was not adjusted for weight changes. Mice were treated with vehicle or PX-866 every other day for up to 4 weeks.

\section{Western Blots}

Western blot analysis was performed on lung homogenates as previously described. ${ }^{20}$ Blots were incubated with antibodies against total and phosphorylated Akt (Ser 473 and Thr 308, Cell Signaling Technology) and quantified using the volume integration function on a Phosphorlmager software Imagequant 5.2 (Molecular Dynamics, Sunnyvale, CA).

\section{Lung Histology, Immunostaining, and Total Lung Collagen}

Lungs were inflation fixed as previously described. ${ }^{21}$ Sections (5 $\mu \mathrm{m})$ were loaded onto poly-lysine slides for trichrome and smooth muscle $\alpha$-actin (SMA) staining as previously described. ${ }^{22,23}$ Total lung collagen was determined by quantifying total soluble collagen (Sircol Colla-
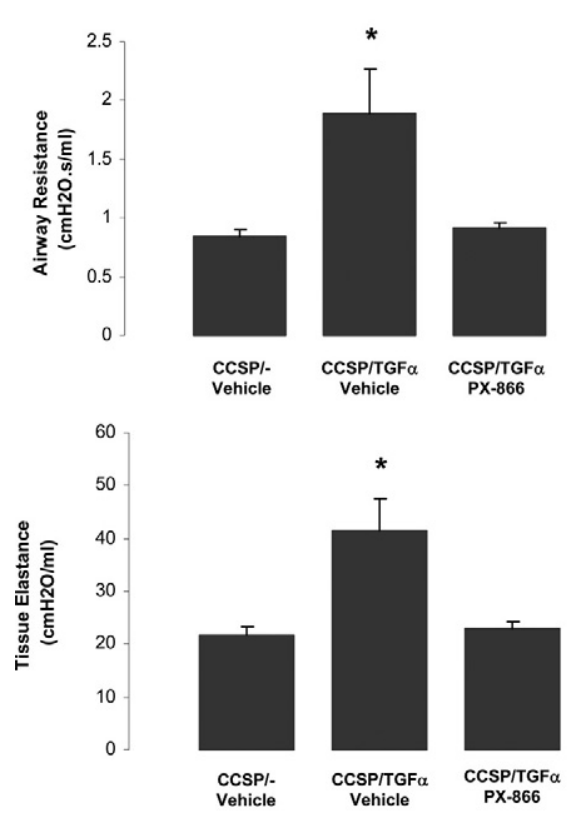
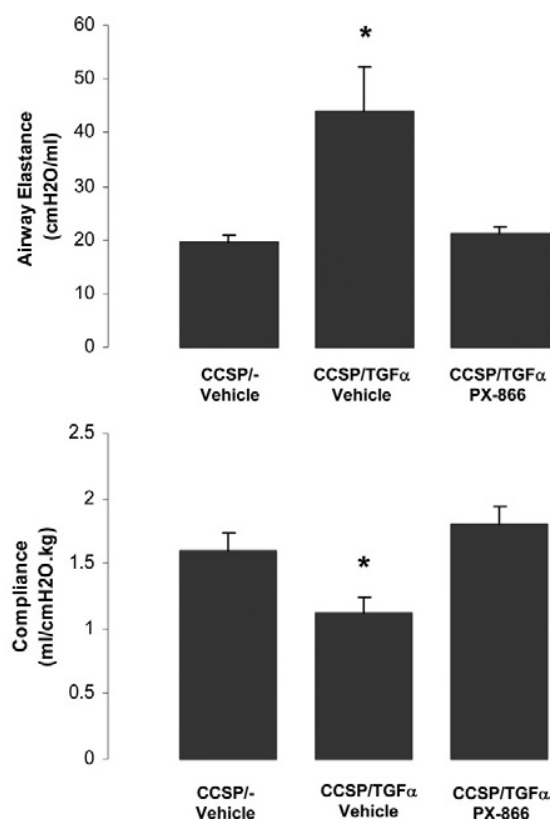

Figure 4. PX-866 prevents TGF $\alpha$-dependent changes in lung function. Pulmonary mechanics were determined as described in Methods. PX866 administered at the time of TGF $\alpha$-induction prevented increases in airway resistance, airway and tissue elastance, and decreases in compliance compared with vehicle-treated CCSP/TGF $\alpha$ transgenic mice receiving 4 weeks of Dox. ${ }^{*} P<$ 0.05 , as compared with $\mathrm{CCSP} /-$ controls and PX-866-treated mice. Data were derived from six to ten mice in each group. 
gen Assay, Biocolor, County Antrim, Ireland) as previously described. ${ }^{20}$

\section{Pulmonary Mechanics}

Lung mechanics were assessed on mice with a computerized Flexi Vent system (SCIREQ, Montreal, Canada), as previously described. ${ }^{24,25}$ Briefly, mice were anesthetized with ketamine and xylazine, tracheostomized, and then ventilated with a tidal volume of $8 \mathrm{ml} / \mathrm{kg}$ at a rate of 150 breaths/min and positive end-expiratory pressure of $2 \mathrm{~cm} \mathrm{H} \mathrm{H}_{2} \mathrm{O}$ computerized by the SCIREQ system, thereby permitting analysis of dynamic lung compliance, airway resistance, and airway elastance. The ventilation mode was changed to forced oscillatory signal $(0.5$ to $19.6 \mathrm{~Hz})$, and respiratory impedance was measured. Tissue elastance was obtained for mice at $2 \mathrm{~cm} \mathrm{H} \mathrm{H}_{2} \mathrm{O}$ positive endexpiratory pressure by fitting a model to each impedance spectrum. With this system, the calibration procedure removed the impedance of the equipment and tracheal tube.

\section{Statistics}

Means ( \pm SEM) were calculated and plotted for each variable, by mouse group (CCSP/-Vehicle, CCSP/TGF $\alpha$ Vehicle, CCSP/TGF $\alpha$ PX-866, CCSP/TGF $\alpha$ Vehicle Off Dox). Data were assessed for normality using plots and the Shapiro-Wilk test. Where normality assumptions were not met, log-transformed values were used in a one-way analysis of variance to test for differences between groups. Where log-transformations did not improve normality a non-parametric, one-way analysis of variance was used. Simulation-based, step-down multiple comparison adjustments were used for all pair-wise comparisons. (For the nonparametric analyses of variance, the Bonferroni-Holm multiple comparison adjustment was used.) The significance level was set a priori at $P<0.05$. Weights of mice in four different groups were measured at baseline and at weekly intervals over the ensuing 8 weeks. A repeated measures analysis was conducted with Group $\times$ Time and Baseline as the factors, to compute differences in Group $\times$ Time means. A separate Toepliz variance/covariance structure was used for each Group. Differences in selected (a priori) Group $\times$ Time means were calculated and tested using a simulationbased adjustment for multiple comparisons.

\section{Results}

\section{PX-866 Inhibits TGF $\alpha$-Induced Phosphorylation of $A k t$}

CCSP/TGF $\alpha$ mice were treated with Dox for 1 day to induce TGF $\alpha$ expression. Phosphorylated Akt (P-Akt) levels for Ser 473 as measured by Western blot analysis increased over fivefold compared with Dox-treated CCSP/- control mice. PX-866 treatment in CCSP/TGF $\alpha$ mice prevented TGF $\alpha$-induced increases in P-Akt (Figure $1, \mathrm{~A}$ and $\mathrm{B})$.

\section{PX-866 Inhibits TGF $\alpha$-Induced Pulmonary Fibrosis}

CCSP/TGF $\alpha$ mice were treated with Dox to induce TGF $\alpha$ expression and concomitantly treated with either PX-866 (3 mg/kg) or vehicle every other day for 4 weeks. Induction of TGF $\alpha$ caused extensive pleural, perivascular, and peribronchial fibrosis (Figure 2A). Total lung collagen levels were over twofold higher in CCSP/TGF $\alpha$ mice compared with Dox-treated CCSP/- control mice after 4 weeks of Dox. Mice treated with PX-866 did not show any differences in lung fibrosis as assessed by histology and whole lung collagen compared with Dox-treated CCSP/control mice (Figure 2, A and B). Similarly, induction of TGF $\alpha$ caused marked increases in SMA staining in fibrotic regions that were prevented in PX-866-treated mice (Figure 3). Lung compliance decreased by more

\section{A}

\begin{tabular}{|c|c|c|}
\hline Group & On Dox & Vehicle \\
\hline & On Dox & Vehicle \\
\hline & On Dox & PX-866 \\
\hline & On Dox & Vehicle \\
\hline
\end{tabular}

B

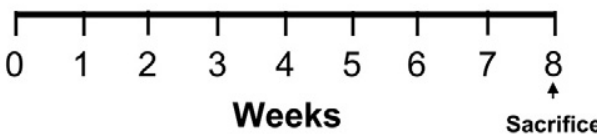

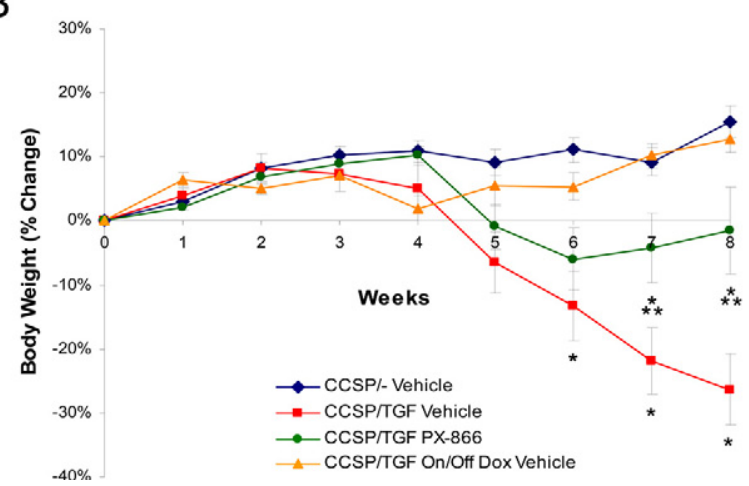

Figure 5. PX-866 prevents progressive weight loss. To assess the efficacy of $\mathrm{PI} 3 \mathrm{~K}$ inhibition in established fibrosis, CCSP/TGF $\alpha$ transgenic mice were treated with PX-866 after 4 weeks of Dox, while remaining on Dox for an additional 4 weeks. The treatment protocol is represented schematically in $\mathbf{A}$ Controls included CCSP/ - and CCSP/TGF $\alpha$ mice treated with vehicle while remaining on Dox an additional 4 weeks. Mice were weighed weekly during treatments as described in Materials and Methods. Dox-induced expression of TGF $\alpha$ for 8 weeks caused progressive weight loss in vehicle-treated mice (red line), while mice treated with PX-866 4 weeks after TGF $\alpha$ induction did not have changes in body weight (green line), but weights remained below $\mathrm{CCSP} /-$ controls (blue line), and CCSP/TGF $\alpha$ mice that received 4 weeks of Dox, then taken off Dox and treated with 4 weeks of vehicle (gold line, B). ${ }^{*} P<0.05$ compared with CCSP $/-$ control mice and CCSP/TGF $\alpha$ transgenic Off Dox mice; ${ }^{* *} P<0.05$ compared with vehicle-treated CCSP/TGF $\alpha$ transgenic mice. Data derived from 10 mice per group. 


\section{A CCSP/TGFa Vehicle}

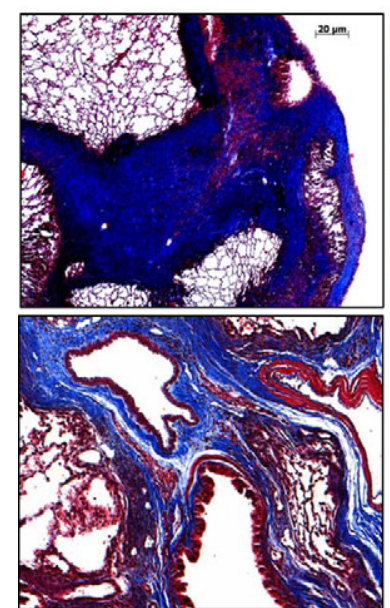

CCSP/TGFa

PX-866

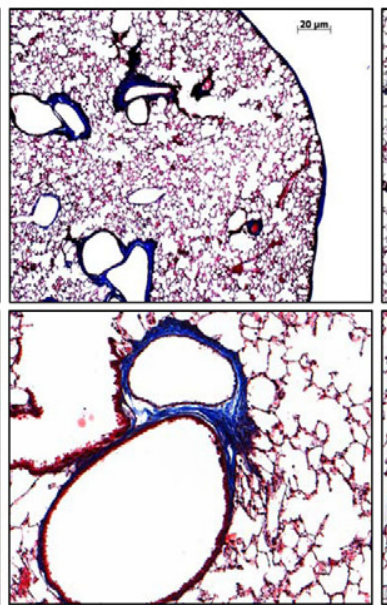

CCSP/TGFa On/Off Dox

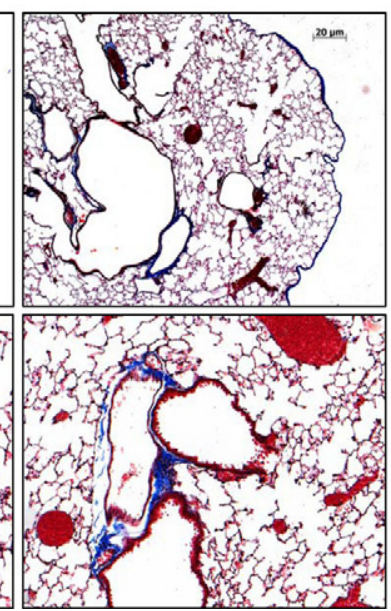

B

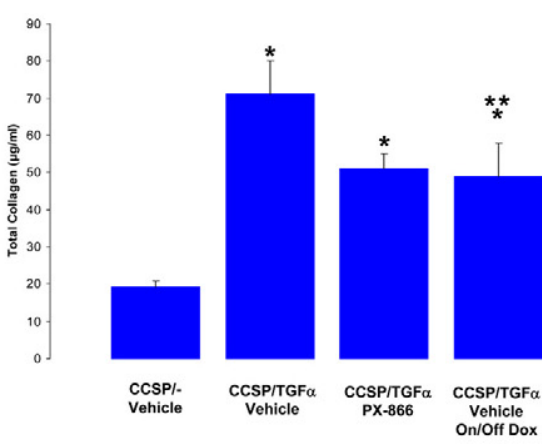

Figure 6. PX-866 decreases progression of lung fibrosis. Both CCSP/TGF $\alpha$ transgenic mice administered PX-866 4 weeks after the initiation of TGF $\alpha$ induction and CCSP/TGF $\alpha$ transgenic mice Off Dox demonstrated attenuation of fibrosis compared with vehicle-treated CCSP/TGF $\alpha$ mice. Photomicrographs in $\mathbf{A}$ are trichrome stains from two separate animals focused on low power of pleural surface and interstitial areas (top, $\times 2.5$ magnification) and higher power of peribronchial and perivascular adventitium (bottom, $\times 10$ magnification). All photomicrographs are representative of lungs from six mice in each group. Panel B demonstrates lung collagen in PX-866-treated mice was unchanged compared with Off Dox mice, but remained elevated compared with CCSP - controls. ${ }^{*} P<$ 0.05 compared with CCSP $/-$ control mice; ${ }^{* *} P<0.05$ compared with vehicle-treated CCSP/TGF $\alpha$ transgenic mice. Data derived from 10 mice per group.

than $30 \%$, and airway resistance, elastance and tissue elastance increased more than twofold in CCSP/TGF $\alpha$ mice compared with Dox-treated CCSP/- control mice (Figure 4). Mice treated with PX-866 did not show any differences in lung mechanics compared with Doxtreated control mice (Figure 4).

\section{PX-866 Prevents Progression of Established TGF $\alpha$-Induced Pulmonary Fibrosis}

To determine whether PX-866 influences the progression of established fibrosis, following 4 weeks of Dox treatment, CCSP/TGF $\alpha$ mice were administered PX-866, while remaining on Dox for an additional 4 weeks (8 weeks total) (Figure 5A). Controls included CCSP/- and CCSP/ TGF $\alpha$ mice treated with vehicle while remaining on Dox an additional 4 weeks. A third set of controls included CCSP/TGF $\alpha$ mice that received 4 weeks of Dox, then taken off Dox and treated with 4 weeks of vehicle. The on-off Dox group is added to compare the efficacy of PX-866 in reversing fibrosis in mice with ongoing EGFR activation to mice where EGFR activation is extinguished. ${ }^{14}$

Body weights of CCSP/TGF $\alpha$ mice treated with vehicle decreased over $26 \%$ from baseline following 8 weeks of Dox (Figure 5B). PX-866 administered at the beginning of week 5 prevented further body weight loss compared with vehicle-treated CCSP/TGF $\alpha$ mice, but body weights were still lower than CCSP/- control mice or CCSP/TGF $\alpha$ mice off Dox. CCSP/TGF $\alpha$ mice treated with Dox and vehicle for 8 weeks demonstrated marked pleural thickening with fibrosis advancing into the interstitium and effacing alveolar architecture as assessed on histology with trichrome and SMA stain (Figure 6A and Figure 7). In addition, there was also advanced perivascular and peribronchial fibrosis affecting large and small vessels and airways. CCSP/TGF $\alpha$ mice treated with PX-866 demon- strated reduced pleural fibrosis, as well as reduced perivascular and peribronchial fibrosis, as compared with vehicle-treated mice. CCSP/TGF $\alpha$ mice off Dox also demonstrated similar reductions in pleural and adventitial fibrosis with little fibrosis detected in small airways and vessels. Total lung collagen levels were almost fourfold higher in CCSP/TGF $\alpha$ mice, as compared with Doxtreated CCSP/- control mice after 8 weeks of Dox (Figure $6 \mathrm{~B})$. Both CCSP/TGF $\alpha$ mice treated with PX-866 and mice off Dox demonstrated reduced lung collagen levels compared with vehicle-treated mice, but levels remained significantly elevated compared with CCSP/- control mice (Figure 6B). Lung mechanics of CCSP/TGF $\alpha$ mice treated with PX-866 were significantly improved, as compared with vehicle-treated mice, but also remained significantly altered, as compared with controls and CCSP/TGF $\alpha$ mice off Dox for 4 weeks (Figure 8).

\section{Discussion}

The present study demonstrates that treatment with the PI3K inhibitor PX-866 prevents EGFR-mediated pulmonary fibrosis and associated alterations in lung mechanics in TGF $\alpha$ transgenic mice. These findings support the PI3K pathway as a primary signaling pathway downstream of EGFR mediating pulmonary fibrogenesis.

To more closely mirror clinical treatment of individuals with lung fibrosis, we also evaluated whether PI3K signaling is necessary for maintenance and/or progression of established TGF $\alpha$-induced fibrosis. Mice treated with PX-866 4 weeks after Dox demonstrated normalization of body weights, reduced fibrosis on lung histology and improved lung mechanics compared with vehicle-treated mice. However, body weights, lung histology, lung collagen, and lung mechanics all remained altered compared 


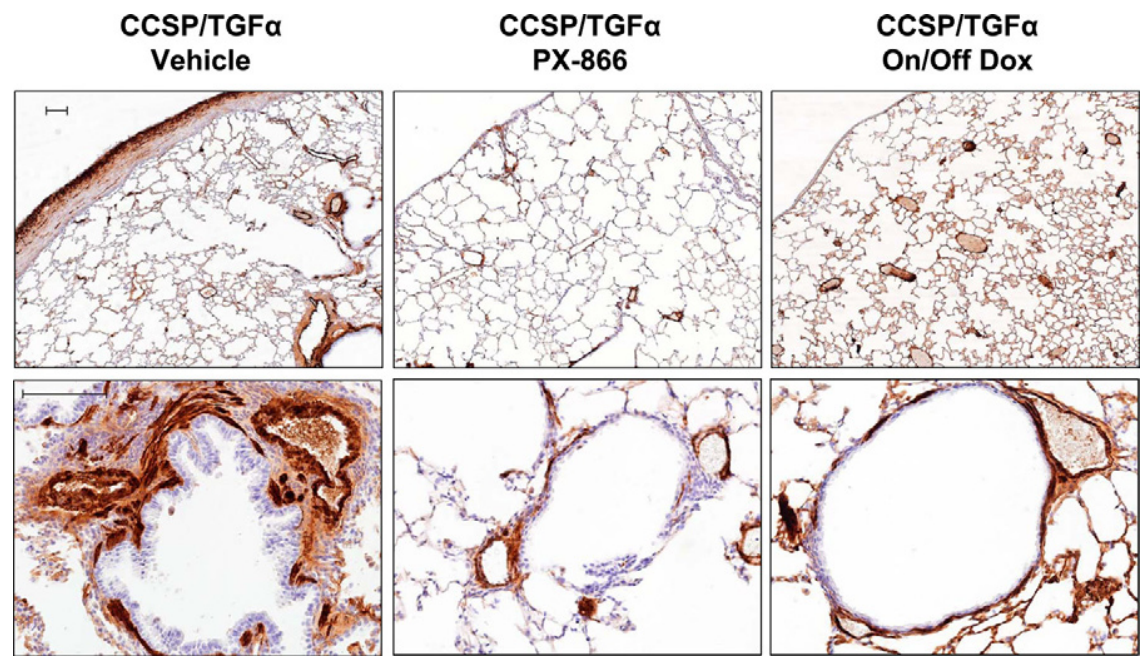

Figure 7. PX-866 decreases progression of SMA deposition. Sections of lungs from CCSP/TGF $\alpha$ transgenic mice in reversal studies were stained with SMA. CCSP/TGF $\alpha$ transgenic mice administered vehicle demonstrate marked SMA staining in the pleural and adventitia regions while mice treated with PX-866 and Off Dox demonstrate reduced SMA staining. Upper panel is taken at $\times 5$ magnification with lower panel at $\times 20$ magnification. Scale bar $=100 \mu \mathrm{m}$. Photomicrographs are from two separate animals and are representative of lungs from five to seven mice in each group.

with CCSP/- control mice demonstrating incomplete reversal of the fibrosis phenotype. As the fibrotic process may not be expected to be completely resolved 4 weeks into treatment, we compared endpoints to mice where TGF $\alpha$ over-expression was extinguished by removing Dox. If fibrosis endpoints were similar between the PX866 and Off Dox groups, PI3K inhibition is likely to be effective in reversing lung fibrosis. Our results demonstrate PX-866 treated mice showed similar degrees of fibrosis measured by lung collagen and histology compared with mice Off Dox, while physiological measures of fibrosis including body weights and lung mechanics remained altered in PX-866-treated mice.

To further assess PI3K inhibition in reversing fibrosis we compared PX-866-treated mice to mice after only 4 weeks of Dox. Fibrosis endpoints in the 4-week Dox group (Figures 2-4) represent the new starting point of lung fibrosis when mice begin treatment. If PI3K inhibition reversed fibrosis then endpoints would be improved, as compared with 4 weeks Dox mice. PX-866-treated mice demonstrated similar degrees of fibrosis measured by lung histology and collagen, as compared with 4-week
Dox mice, while lung mechanics remained significantly altered in PX-866-treated mice.

Taken together, these reversal studies demonstrate that inhibition of PI3K with PX-866 after fibrosis is established prevented progression of lung fibrosis but attenuated physiological alterations. One explanation for these findings is that additional time may be necessary to allow more fibrosis resolution to be detected in PX-866-treated mice. While we did not measure lung collagen or mechanics values between 4 and 8 weeks of treatment, the weekly body weight values in the PX-866-treated mice trended upward for the final 2 weeks of treatment, suggesting a delayed recovery. Another explanation is that additional signaling pathways other than PI3K remain activated and continue to contribute toward maintenance of lung fibrosis. Tyrosine kinase receptors such as EGFR activate the PI3K and other pathways that control cellular growth and proliferation. The concept of combined signaling pathway inhibition has proved effective in transgenic and xenograft models of cancer. ${ }^{26-28}$ Identification of additional signaling pathways active in the mainte-
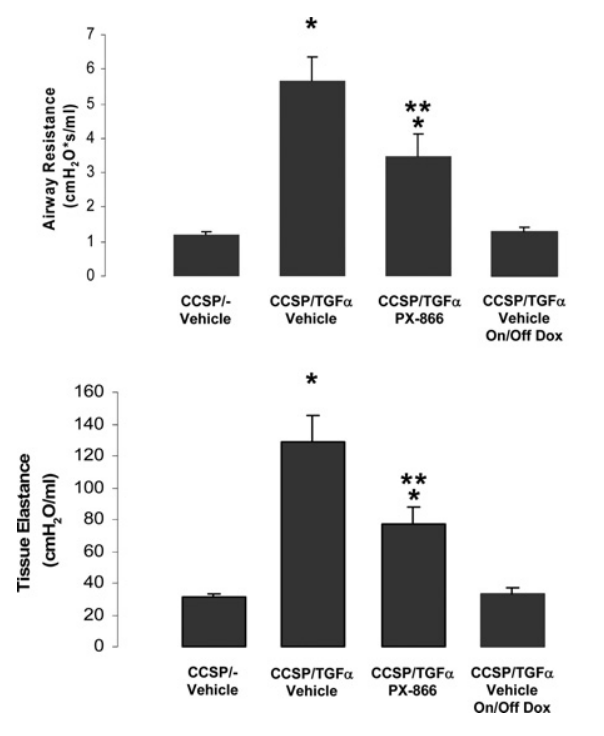
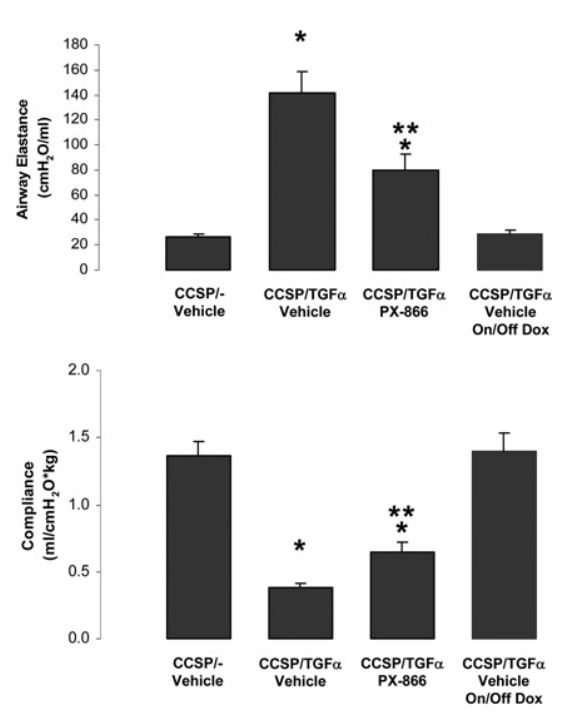

Figure 8. PX-866 slows progression of TGF $\alpha$ dependent changes in lung mechanics. CCSP TGF $\alpha$ transgenic mice administered PX-866 4 weeks after treatment with Dox demonstrated reduced increases in airway resistance, and airway and tissue elastance, and decreases in compliance, as compared with vehicle-treated CCSP/ TGF $\alpha$ transgenic mice receiving 8 weeks of Dox. Lung mechanics in PX-866 mice were significantly altered compared with controls and CCSP/TGF $\alpha$ mice Off Dox for 4 weeks. ${ }^{*} P<0.05$ compared with CCSP/ - control mice and CCSP/ TGF $\alpha$ transgenic mice Off Dox; ${ }^{* *} P<0.05$ compared with vehicle-treated CCSP/TGF $\alpha$ transgenic mice. Data derived from 10 mice per group. 
nance of lung fibrosis would support combined targeted therapy.

Fibrosis induced by 4 weeks of TGF $\alpha$ expression, followed by TGF $\alpha$ extinction demonstrated physiological reversal based on changes in body weights (Figure 5B) and lung mechanics (Figure 8) and minimal residual fibrosis on lung histology and collagen measurements (Figures 6 and 7). These results support previous data in TGF $\alpha$ mice demonstrating near complete reversal of fibrosis following extinction of TGF $\alpha$ expression after 6 weeks of overexpression. ${ }^{14}$ Together these findings support the concept that maintenance of lung fibrosis requires ongoing exposure to pro-fibrotic stimuli. Moreover, these findings support that the lung, like the liver, is capable of reversing established fibrosis. ${ }^{29}$

Emerging data from other studies support the data that PI3K activation mediates lung fibrosis. Studies in both human and mouse fibroblasts demonstrate that PI3K activation leads to reduced apoptosis along with increased proliferation, collagen synthesis and myofibroblasts differentiation. ${ }^{30-32}$ Tumor suppressor phosphatase and tensin homolog (PTEN) is a negative growth regulator of the PI3K-Akt pathway that de-phosphorylates phosphatidylinositol (3,4,5)-triphosphate to phosphatidylinositol $(4,5)$-biphosphate. Bleomycin lung injury of PTEN-haploinsufficient and wild-type mice treated with a pharmacological inhibitor of PTEN causes augmented collagen deposition and myofibroblast differentiation supporting a role in vivo for unopposed PI3K-Akt activation in the pathogenesis of pulmonary fibrosis. ${ }^{30,31}$ Fibroblasts isolated from patients with idiopathic pulmonary fibrosis have decreased PTEN expression or decreased PTEN activity leading to increased proliferation. ${ }^{31,33}$ Pulmonary fibrosis in lung-specific regulatable TGF $\beta 1$ transgenic mice was attenuated when mice were treated with an Akt inhibitor. ${ }^{34}$ Fibrosis in TGF $\alpha$ transgenic mice develops independent of TGF $\beta$ activation suggesting the PI3K/Akt pathway may represent a potential point of convergence where multiple pro-fibrotic stimuli converge to induced mesenchymal cell proliferation and matrix deposition. The platelet derived growth factor is another profibrotic growth factor implicated in inflammatory models of lung fibrosis. ${ }^{35,36}$ Platelet-derived growth factors act via two receptors that, like EGFR, are receptor tyrosine kinases. Like EGFR and TGF $\beta 1$, platelet-derived growth factor receptors activate PI3K ${ }^{37}$ Collectively, these data further support a role of PI3K activation as a common pathway mediating fibrogenesis induced by multiple cytokines.

Both epithelial cells and mesenchymal cells proliferate in response to TGF $\alpha,{ }^{13,22}$ however it is unclear if PI3K activation in both cell types leads to fibrosis. Transgenic mice in which the Pten gene was conditionally deleted from the pulmonary epithelium demonstrated increased epithelial PI3K-Akt activation associated with marked epithelial hyperplasia characterized by a hypercellular epithelium lining papillae with fibrovascular cores that protruded into bronchial and bronchiolar lumens. ${ }^{38}$ However, unlike TGF $\alpha$ transgenic mice, the hyperplasia was not progressive, and parenchymal fibrosis did not develop suggesting that PI3K activation of the fibroblast is important in mediating PI3K/Akt-mediated fibrosis.
Recent data support that activation of PI3K-Akt is a cause of human fibrotic lung disease. Immunohistochemical analysis of lung biopsies from idiopathic pulmonary fibrosis patients demonstrate increased phosphorylated Akt in fibroblastic foci. ${ }^{31}$ The success of PI3K inhibition in the TGF $\alpha$ and TGF $\beta$ transgenic models coupled with evidence of aberrant PI3K signaling in human fibrotic disease suggests that pharmacologically targeting the PI3K-Akt pathway may alter progressive fibrosis in human diseases. However, a broad range of cellular processes mediated by PI3K may be affected by inhibitors posing significant risks. ${ }^{39}$ Safety data on patients treated with PI3K inhibition is forthcoming as PX-866 is currently in Phase 1 clinical trials as an antitumor agent.

In summary, the present study provides insight into the molecular mechanisms of TGF $\alpha$ /EGFR-mediated pulmonary fibrosis. These findings support the concept that PI3K activation may play a significant role in human lung fibrotic disease, which could be amenable to targeted therapy.

\section{Acknowledgments}

We thank the veterinary services at Cincinnati Children's Hospital Medical Center for their expert care of mice used in this study. In addition, we thank Angelica Schehr for technical assistance in measuring lung mechanics and assistance with statistical analysis by Rhonda Vandyke, Ph.D.

\section{References}

1. Cook DN, Brass DM, Schwartz DA: A matrix for new ideas in pulmonary fibrosis. Am J Respir Cell Mol Biol 2002, 27:122-124

2. Kubiak J, Mitra MM, Steve AR, Hunt JD, Davies P, Pitt BR: Transforming growth factor-alpha gene expression in late-gestation fetal rat lung. Pediatr Res 1992, 31:286-290

3. Peschon JJ, Slack JL, Reddy P, Stocking KL, Sunnarborg SW, Lee DC, Russell WE, Castner BJ, Johnson RS, Fitzner JN, Boyce RW, Nelson N, Kozlosky CJ, Wolfson MF, Rauch CT, Cerretti DP, Paxton RJ, March CJ, Black RA: An essential role for ectodomain shedding in mammalian development. Science 1998, 282:1281-1284

4. Polosa R, Prosperini G, Leir SH, Holgate ST, Lackie PM, Davies DE: Expression of $\mathrm{C}$-erbB receptors and ligands in human bronchial mucosa. Am J Respir Cell Mol Biol 1999, 20:914-923

5. Fernandes AM, Hamburger AW, Gerwin BI: Production of epidermal growth factor related ligands in tumorigenic and benign human lung epithelial cells. Cancer Lett 1999, 142:55-63

6. Dammann CE, Nielsen HC, Carraway KL 3rd: Role of neuregulin-1 beta in the developing lung. Am J Respir Crit Care Med 2003 167:1711-1716

7. Lemjabbar H, Li D, Gallup M, Sidhu S, Drori E, Basbaum C: Tobacco smoke-induced lung cell proliferation mediated by tumor necrosis factor alpha-converting enzyme and amphiregulin. J Biol Chem 2003, 278:26202-26207

8. Vermeer PD, Einwalter LA, Moninger TO, Rokhlina T, Kern JA, Zabner $\mathrm{J}$, Welsh MJ: Segregation of receptor and ligand regulates activation of epithelial growth factor receptor. Nature 2003, 422:322-326

9. Carpenter G: ErbB-4: mechanism of action and biology. Exp Cell Res 2003, 284:66-77

10. Citri A, Skaria KB, Yarden $Y$ : The deaf and the dumb: the biology of ErbB-2 and ErbB-3. Exp Cell Res 2003, 284:54-65

11. Bogdan S, Klambt C: Epidermal growth factor receptor signaling Curr Biol 2001, 11:R292-R295

12. Jorissen RN, Walker F, Pouliot N, Garrett TP, Ward CW, Burgess AW: 
Epidermal growth factor receptor: mechanisms of activation and signalling. Exp Cell Res 2003, 284:31-53

13. Hardie WD, Le Cras TD, Jiang K, Tichelaar JW, Azhar M, Korfhagen TR: Conditional expression of transforming growth factor-alpha in adult mouse lung causes pulmonary fibrosis. Am J Physiol Lung Cell Mol Physiol 2004, 286:L741-L749

14. Hardie WD, Korfhagen TR, Sartor MA, Prestridge A, Medvedovic M, Le Cras TD, Ikegami M, Wesselkamper SC, Davidson C, Dietsch M, Nichols W, Whitsett JA, Leikauf GD: Genomic profile of matrix and vasculature remodeling in TGF-\{alpha\} induced pulmonary fibrosis. Am J Respir Cell Mol Biol 2007, 37:309-321

15. Cantley LC: The phosphoinositide 3-kinase pathway. Science 2002, 296:1655-1657

16. Ihle NT, Paine-Murrieta G, Berggren MI, Baker A, Tate WR, Wipf $P$, Abraham RT, Kirkpatrick DL. Powis G: The phosphatidylinositol-3kinase inhibitor PX-866 overcomes resistance to the epidermal growth factor receptor inhibitor gefitinib in A-549 human non-small cell lung cancer xenografts. Mol Cancer Ther 2005, 4:1349-1357

17. Ihle NT, Williams R, Chow S, Chew W, Berggren MI, Paine-Murrieta G, Minion DJ, Halter RJ, Wipf P, Abraham R, Kirkpatrick L, Powis G: Molecular pharmacology and antitumor activity of PX-866, a novel inhibitor of phosphoinositide-3-kinase signaling. Mol Cancer Ther 2004, 3:763-772

18. Ihle NT, Lemos R Jr, Wipf P, Yacoub A, Mitchell C, Siwak D, Mills GB, Dent $P$, Kirkpatrick DL, Powis G: Mutations in the phosphatidylinositol-3-kinase pathway predict for antitumor activity of the inhibitor PX-866 whereas oncogenic Ras is a dominant predictor for resistance. Cancer Res 2009, 69:143-150

19. Tichelaar JW, Lu W, Whitsett JA: Conditional expression of fibroblast growth factor-7 in the developing and mature lung. J Biol Chem 2000, 275:11858-11864

20. Hardie WD, Davidson C, Ikegami M, Leikauf GD, Le Cras TD, Prestridge A, Whitsett JA, Korfhagen TR: EGF receptor tyrosine kinase inhibitors diminish transforming growth factor-alpha-induced pulmonary fibrosis. Am J Physiol Lung Cell Mol Physiol 2008, 294:L1217-L1225

21. Garvey W, Fathi A, Bigelow F, Carpenter B, Jimenez C: Improved Movat pentachrome stain. Stain Technol 1986, 61:60-62

22. Hardie WD, Piljan-Gentle A, Dunlavy MR, Ikegami M, Korfhagen TR: Dose-dependent lung remodeling in transgenic mice expressing transforming growth factor-alpha. Am J Physiol Lung Cell Mol Physiol 2001, 281:L1088-L1094

23. Le Cras TD, Hardie WD, Fagan K, Whitsett JA, Korfhagen TR: Disrupted pulmonary vascular development and pulmonary hypertension in transgenic mice overexpressing transforming growth factor\{alpha\}. Am J Physiol Lung Cell Mol Physiol 2003, 285(5):L1046-L1054

24. Schuessler TF, Bates JH: A computer-controlled research ventilator for small animals: design and evaluation. IEEE Trans Biomed Eng $1995,42: 860-866$

25. Hokuto I, Ikegami M, Yoshida M, Takeda K, Akira S, Perl AK, Hull WM, Wert SE, Whitsett JA: Stat-3 is required for pulmonary homeostasis during hyperoxia. J Clin Invest 2004, 113:28-37

26. Engelman JA, Chen L, Tan X, Crosby K, Guimaraes AR, Upadhyay R,
Maira M, McNamara K, Perera SA, Song Y, Chirieac LR, Kaur R, Lightbown A, Simendinger J, Li T, Padera RF, Garcia-Echeverria C, Weissleder R, Mahmood U, Cantley LC, Wong KK: Effective use of PI3K and MEK inhibitors to treat mutant Kras G12D and PIK3CA H1047R murine lung cancers. Nat Med 2008, 14:1351-1356

27. Downward J: Targeting RAS and PI3K in lung cancer. Nat Med 2008, $14: 1315-1316$

28. Li D, Shimamura T, Ji H, Chen L, Haringsma HJ, McNamara K, Liang MC, Perera SA, Zaghlul S, Borgman CL, Kubo S, Takahashi M, Sun Y, Chirieac LR, Padera RF, Lindeman NI, Janne PA, Thomas RK, Meyerson ML, Eck MJ, Engelman JA, Shapiro GI, Wong KK: Bronchial and peripheral murine lung carcinomas induced by T790M-L858R mutant EGFR respond to $\mathrm{HKI}-272$ and rapamycin combination therapy. Cancer Cell 2007, 12:81-93

29. Wynn TA: Common and unique mechanisms regulate fibrosis in various fibroproliferative diseases. J Clin Invest 2007, 117:524-529

30. White ES, Atrasz RG, Hu B, Phan SH, Stambolic V, Mak TW, Hogaboam CM, Flaherty KR, Martinez FJ, Kontos CD, Toews GB: Negative regulation of myofibroblast differentiation by PTEN (phosphatase and tensin homolog deleted on chromosome 10). Am J Respir Crit Care Med 2006 173:112-121

31. Xia H, Diebold D, Nho R, Perlman D, Kleidon J, Kahm J, Avdulov S, Peterson M, Nerva J, Bitterman P, Henke C: Pathological integrin signaling enhances proliferation of primary lung fibroblasts from patients with idiopathic pulmonary fibrosis. J Exp Med 2008, 205:1659-1672

32. Nho RS, Xia H, Diebold D, Kahm J, Kleidon J, White E, Henke CA PTEN regulates fibroblast elimination during collagen matrix contraction. J Biol Chem 2006, 281:33291-33301

33. White ES, Thannickal VJ, Carskadon SL, Dickie EG, Livant DL, Markwart $\mathrm{S}$, Toews GB, Arenberg DA: Integrin alpha4beta1 regulates migration across basement membranes by lung fibroblasts: a role for phosphatase and tensin homologue deleted on chromosome 10. Am J Respir Crit Care Med 2003, 168:436-442

34. Kang HR, Lee CG, Homer RJ, Elias JA: Semaphorin 7A plays a critical role in TGF-beta1-induced pulmonary fibrosis. J Exp Med 2007, 204:1083-1093

35. Rice AB, Moomaw CR, Morgan DL, Bonner JC: Specific inhibitors of platelet-derived growth factor or epidermal growth factor receptor tyrosine kinase reduce pulmonary fibrosis in rats. Am J Pathol 1999, 155:213-221

36. Abdollahi A, Li M, Ping G, Plathow C, Domhan S, Kiessling F, Lee LB, McMahon G, Grone HJ, Lipson KE, Huber PE: Inhibition of plateletderived growth factor signaling attenuates pulmonary fibrosis. J Exp Med 2005, 201:925-935

37. Andrae J, Gallini R, Betsholtz C: Role of platelet-derived growth factors in physiology and medicine. Genes Dev 2008, 22:1276-1312

38. Dave V, Wert SE, Tanner T, Thitoff AR, Loudy DE, Whitsett JA: Conditional deletion of Pten causes bronchiolar hyperplasia. Am J Respir Cell Mol Biol 2008, 38:337-345

39. Sawyers CL: Will kinase inhibitors have a dark side? N Engl J Med 2006, 355:313-315 